12th.-Ice-cap left off. Custard pudding added to the diet. Pain and friction on the right side.

14th.-No friction.

16th. - The temperature had gradually fallen since the 6th, and is normal to.day for the first time; after this it did not exceed the normal. He is extremely weak, lies on his back, and cannot move any part excepting his arms, and these only by a very great effort. He has become very thin, and his face has an anxious, drawn expression. He takes food well. The amount of brandy was gradually reduced and the diet improved. The bowels were kept open by enemata consisting of two drachms of glycerine. The albuminuria had disappeared on the 2lst, and the pains ceased about the same time. The condition of the lungs gradually improved, and the salicylate of soda was stopped on the $25 \mathrm{th}$, when four ounces of port wine were substituted for the brandy and tonics given.

March 6th.- The patient sits up in bed, and his strength has improved. He is putting on flesh.

8th.-Looks very anæmic. Corpuscles are normal in number, but the hæmoglobin is only 54 per cent. Two grains of sulphate of iron in a mixture three times a day.

11th. -Got up, but was unable to stand.

22nd.-Much stouter, weighs 8 st. $12 \mathrm{lb}$, being 2 st. less than before the illness.

The anæmia rapidly disappeared, and when he left the hospital on April 9th to go to a convalescent home, the hæmoglobin had increased to 75 per cent. (Gowers' hæma. cytometer and hæmoglobinometer were used in these estimations.) His weight was 9 st. $11 \frac{1}{2} \mathrm{lb}$. On May 2nd he returned from the convalescent home, and weighed 10 st. $7 \mathrm{lb}$

Remarks by Dr. SaInsbury.-Though the patient had been subject to chronic rheumatism, there was no history of a previous acute attack, so that the case should probably be included as one of hyperpyrexia during a first attack of rheumatic fever. The pneumonia present (a frequent complication of hyperpyrexia) appeared to be of the hypostatic or passive congestive kind, as evidenced by the rather indefinite signs of an impaired note and a weakened breath sound, accompanied by subcrepitant râles, but against this interpretation was its early appearance (the patient came in with it) and the fact that the vascular system was the one system which constituted the pièce de résistance, and did not show signs of giving way. To this I would draw special attention-viz, that whilst the nervous system reacted in the early stages by delirium to the high temperature, and that later, when the temperature had become more moderate, the delirium still persisted, having then assumed the muttering type, and being associated with marked tremor of the hands, the pulse throughout was never unduly accelerated. In the early stage it was most striking how the pulse curve followed the temperature curve; the chart shows this. It was not less striking how, during the third week, in presence of the asthenic delirium, and with a temperature ranging between $103^{\circ}$ and $104^{\circ}$, it averaged $108^{\circ}$. At the end of the third week and during the early part of the fourth the highest pulse-rate was 128 , and during this period the pains in the joints were marked-the average even now was under 120 . During the greater part of the fourth week, with the disappearance of the joint pain and the gradual fall of the temperature, the pulse became quite moderate, averaging about 100. Though the case on several occasions appeared desperate, a favourable prognosis was still suggested by the cardiac strength. The strength of the whole organism proved in this case to be the strength not of its weakest part, but of its strongest. Of what nature was the lung complication? On the theory that it was probably hypostatic, digitalis was given, and in large dose. It was begun on the sixteenth day of the disease, twenty minims being ordered every three hours; this was continued a week, though the interval was made every six hours on the seventh day. The drug did not appear to in. fluence the pneumonia, nor did it seem to affect the pulse or to lessen the delirium. It certainly did not harm the patient, and this tolerance is of considerable interest. The negative influence of digitalis suggests further that the pneumonia was not hypostatic, not due to lessened tone. The ten.perature curve did not seem to be modified by salicylate (twenty grains every three hours); the pains made their appearance during its administration, though they subsequently began to subside on pushing the drug (twenty grains every two hours). During the first twenty.four hours the dose was thirty grains every two hours.

\section{THE GOVERNMENT CIVIL HOSPITAI,} HONG-KONG.

CASE OF ABSCESS OF THE LIVER, WITH COMPLICATIONS: RECOVERY ; REMARKS. ${ }^{k}$

(Under the care of Mr. J. MrtFond Atkinson and Mr. JAMES A. LowsON.)

THE case is of a kind which is very seldom reported in medical works, chiefly because of the rarity with which liver abscesses burst while the patient is in hospital and under constant observation. The patient, J. F-, a Portuguese, aged twenty-two years, who had lived all his life in the East, was admitted to the Government Civil Hospital on Dec. 19th, 1889. When seen in the evening he was suffering from severe erysipelas of the face and scalp, the right side being most affected. His temperature was $103.5^{\circ}$, pulse 100 , and respira tion 36. He was unable to give any history of his state at this time owing to his low condition. He was ordered six teaspoonfuls of castor oil at once, and fifteen minims of tincture of the perchloride of iron and chloroform water with a half drachm of glycerine every four hours. Lead and opium lotion was applied locally with a lint and protective mask, and he was fed on milk, soda water, ice, arrowroot, and brandy.

Afterwards the following history was obtained from him. His family history was good. Patient had always been tem perate. His health, barring one or two slight attacks of inter mittent fever, was good till two years ago, when he contracted syphilis. Shortly afterwards he went to Tonquin, and while there had a large abscess of the left arm, which was opened not far from the shoulder-joint. Fifteen months ago, while still in Tonquin, he had an attack of typhoid fever, which must have been severe, as he had considerable hæemorrhage trom the bowel during the third week, and was in bed for six weeks altogether. He came to Hong Kong again in February, 1889, and shortly afterwards was treated for intermittent fever and "some kind of rheumatism." In the month of May following he got dysentery. Aftera short illness he again became well, and remained fairly healthy till Dec. 9th last. At this time he had a slight attack of intermittent fever, and his face began to swell and get red. He had uccasional rigors a few days later until the time he came into hospital. This condition gradually got worse, with cough and difficulty of breathing. and pains "over most of the body," but chiefly over the right shoulder and in the right side. On Dec. 17th he saw Dr. Hartigan, who advised his removal to hospital.

On the morning of Dec. 20th he was carefully examined. Then he complained chiefly of the coughing, difficulty of breathing, and pain in the breast and between the shoulders and over the right shoulder. Deep inspiration gave great pain in the right side of the chest. On physical examination the liver dulness was considerably enlarged in the right nipple line, reaching from almost half an inch above the nipple to two inches and a half below the free border of the ribs. In the middle line the dulness extended to within an inch and a half of the umbilicus. Posteriorly, the dulness was increased superiorly to the upper border of the eighth rib. Vocal resonance and fremitus were completely absent half an inch below the level of the nipple and below the ninth rib posteriorly. Just at the commencement of the dulness anteriorly and beside the nipple the breath sounds were feeble, the inspiratory sound being distinctly wavy or jerky in character, which, according to some authorities, is probably due to pleuritic adhesions in the neighbourhood not allowing proper expansion of the lung. There were no moist sounds to be heard. The heart sounds were well conducted over to the right side past the nipple. There was some tenderness anteriorly in the right half of the epigastric and right infra-mammary regions. His breath was rery offensive. His stools, which had been light coloured for four or five days before admission, on examination were almost white. Urine, of sp. gr. 1032, contained urates and bile salts in considerable quantity; no albumen. The head and face were in much the same condition as on the previous evening, the skin being quite brawny in parts. Dr. Atkin son agreed that he was probably sufferin o from an abscess of the liver, and the possibility of successful surgical inter-

I Abstract of a paper read before the Hong-Kong Medical Society by Mr. Lowson, on Feb. 8th, 1890. 
ference was discussed. It was decided to wait, as his low state and the presence of the erysipelas especially made it andesirable to make a wound in the proximity of the liver. The former treatment was continued, and his chest and upper part of abdomen swathed in cotton wool and flannel bandage. The same evening his temperature went up to $106^{\circ} 6^{\circ}$, his pulse being 108 and respiration 31. He was ordered fifteen grains of antipyrin every hour till the temperature fell, and to have brandy frequently in small doses. He had four doses of antipyrin, his temperature falling to $102^{\circ}$ in the early morning.

Dec. 21st. - At 6 A.M. the temperature was $100 \cdot 5^{\circ}$, and kept there during the forenoon and part of the afternoon, during which time he had five grains of quinine every hour. Operative measures were out of the question, the patient's condition being very low. At" 8 P. M. he vomited some milk and chicken broth that he had taken shortly before, and for the next hour coughed almost incessantly. Temperature $1045^{\circ}$; pulse 150 , very feeble; respiration 44 . At 9 P.M. he had another severe attack of coughing, with urgent dyspnœa, and brought up with a rush about six ounces of pus, stained with a small quantity of blood. After this he felt some relief. He had a jacket poultice of linseed meal placed over the right side of his chest and back. At this time bubbling ralles could be heard all round the base of the right lung. Puerile breathing was well marked all over the left lung. As the temperature still kept up, he was ordered aight grains of antipyrin every hour, with brandy and other mourishment as before.

22nd.-In the morning the temperature had fallen to $99^{\circ}$; respiration 32 ; pulse 113 . Bowels were opened twice through the night; motions almost white; no pus or blood. He was kept quiet all day and not examined, taking quinine as on the previous day. In the evening his temperature again rose to $105^{\circ}$. During the whole day the coughing, with expectoration of pus, came on at intervals, but no blood with it to-day. Pulse 132 and respiration 44 at 9 P.M. Antipyrin again ordered, eight grains every hour.

$23 \mathrm{rd}$. - At 6 A. M. the temperature was $1026^{\circ}$, and at $10 \mathrm{~A}$.M. it was $100 \cdot 8^{\circ}$. At this time he expressed himself as feeling much easier. On examination the liver dulness was exactly at the level of the nipple, but the lower border of dulness had materially risen, to the extent of one inch in the median line and three-quarters of an inch in the nipple line. Vocal resonance and fremitus were completely absent half an inch below the right nipple, there being quite a sharp line of demarcation. There was a similar condition below the ninth rib behind, on the right side. Bubbling râles were heard all round the right base, with "jerky inspiration," there being two distinct pauses in the inspiratory sound. He had been expectorating freely most of the night, sleep being titful only five or ten minutes at a time. This morning he had a thymol inhalation, and during the day quinine as before. In the evening his temperature again rose to $1048^{\circ}$. Respiration 40 ; pulse $108-112$, very weak. Antipyrin again ordered as before.

24th. - In spite of the antipyrin his temperature kept up during the night, and this morning it was $103 \cdot 5^{\circ}$. His breath was not so offensive or the expectoration so copious. He was ordered one minim of tincture of aconite (which had been found of great benefit at this hospital in many cases of malarial complications with high fever) every half hour. His temperature came down to $996^{\circ}$ at 3 P.M., after which he again had quinine, five grains, every honr. The erysipelas was improving the area of inflammation being less.

25 th. - At 9 A.M. the temperature was $994^{\circ}$; respiration 34 ; pulse 108 . At 9 P. M the temperature was $101 \cdot 2^{\circ}$; pulse 104; respiration 42 . He expectorated pus most of the day. Beef-tea, milk, and egg-flip formed most of his mourishment, which he now took freely. He said he was much better, and gave us more news of his illness.

26th.-His bowels have been opened regularly during the last few days, sometimes once, sometimes twice; stools always white. The erysipelas still decreasing in area.

27th.-The liver dulness now much diminished below, but still at the lower border of the fourth rib above. Moist sounds were still heard round the base of the right lung.

From this time improvement was maintained. The temperature never rose above $995^{\circ}$, the pulse averaging 77 , and respiration 25 , till he went out of hospital. The expectoration got gradually less and finally practically stopped.

29th. - The base of the right lung posteriorly cleared up. The stools still white, and the breath somewhat offensive.

31st.--The erysipelas almost gone; the liver dulness decreased to four inches and a half anteriorly in the nipple line; the stools slightly yellower.

Jan. 10th.-For the last four days he has been taking a pill of one grain of euonymin, half a grain of ipecacuanha, and one grain of colocynth and hyoscyamus pill at night, with the result that his stools are now almost natural in colour, and the urine is quite clear and free from urates and bile salts. T'he liver dulness now commences at the upper border of the fifth rib, and extends for four inches and a quarter in the nipple line, in the median line the dulness not reaching midway between the episternum and umbilicus. No abnormal sounds in the lungs can be heard, and expansion on deep inspiration is equal on both sides.

Remarks by Mr. Lowson. - I may add that he has again come into hospital with tertiary syphilitic symptoms, and his condition as regards physical signs and symptoms of liver and lungs is what is described as "normal" in text-books. The diagnosis of the abdominal trouble was a tropical abscess of the liver, situated probably in the right lobe, near the convex surface, in an organ already much predisposed to abscess from previous malaria, dysentery, and possibly syphilis. Very few cases of liver abscesses which rupture are diagnosed nowadays before the rupture-most being diagnosed after the rupture or at the necropsy-the improved surgical treatment of these cases almost demanding operation in every case. One hears of large numbers of these abscesses bursting into other organs and getting cured spontaneously in that way, but I am afraid the majority end in quite the reverse manner; in fact, in looking over the medica] records - with the exception of a number of cases mentioned by Sir Joseph Fayrer--most of the not-operated-on cases recorded by the different writers have died. I noticed, by the way, that Mr. Vaughan Harley, in a recent paper before the British Medical Association, never mentions dysentery as a cause of abscess of the liver. I am led to believe that at least 90 per cent. of abscesses in this part of the East result from dy sentery. There is no doubt that on the whole the most favourable ending of a liver abscess is for it to burst through the wall of the abdomen just below the ribs in the right nipple line. How often does this occur? Very seldom. Most frequently other ways or channels are chosen, and of these by the bronchi is, from the limited experience I have on the matter, I think the safesi. Abscesses of the lower part of the liver generally burst by the lower surface, and the dangers of peritonitis or bæmorrhage from large vessels is very great. Very few indeed can be discharged by the bowel with no further complication than a slight and localised peritonitis.

\section{Attevical Sorietites.}

\section{ROYAL MEDICAL \& CHIRURGICAL SOCIETY}

\author{
Senile Hypertrophy and Senile Atrophy of the Skull.-The
} Cure of Leprosy.

AN ordinary meeting of this Society was held on May $27 \mathrm{th}$, the Fresident, Mr. Timothy Holmes, in the chair.

A paper on Senile Hypertrophy and Senile Atrophy of the Skull was communicated by Professor Humphry of Cambridge. Attention was directed to two changes of opposite nature, not uncommon in the skulls of elderly persons, both of which were peculiar to this part of the skeleton, and both of which were rather difficult of ex planation. One consisted of an increase of thickness and an increase of density, and therefore an increase of weight, which seemed to be attributable to a shrinking of the brain with consequent lessening of pressure and increase of congestion of the vessels of the skull which were supplied from the interior, this congestion leading to bone deposition on the inside and condensation of the diploe, and affording a remarkable contrast to the rarefaction and lightening of the bones in other parts of the same subjects. The other change consisted in atrophy from without, contrasting with the atrophy in other bones which proceeded in the main from within. The skull became smaller and lighter, the outer table of the vault approaching the inner, and the skull-wall being consequently reduced in thickness. This change might take place unifornly, or it might proceed in some parts more than in others. The most common parts for the extreme thinning were the parietal bones on the sides of 